\title{
Molecular Mechanisms Separating Two Axonal Pathways during Embryonic Development of the Avian Optic Tectum
}

\author{
Stephen Kröger*+ and Jochen Walter ${ }^{\ddagger}$ \\ *Abteilung Biochemie \\ tPhysikalische Biologie \\ Max-Planck-Institut für Entwicklungsbiologie \\ Spemannstrasse 35 \\ D-7400 Tübingen \\ Germany
}

\section{Summary}

During embryonic development of the avian optic tectum, retinal and tectobulbar axons form an orthogonal array of nerve processes. Growing axons of both tracts are transiently very closely apposed to each other. Despite this spatial proximity, axons from the two pathways do not intermix, but instead restrict their growth to de fined areas, thus forming two separate plexiform layers, the stratum opticum and the stratum album centrale. In this study we present experimental evidence indicating that the following three mechanisms might play a role in segregating both axonal populations: Retinal and tectobulbar axons differ in their ability to use the extracellular matrix protein laminin as a substrate for axonal elongation; the environment in the optic tectum is generally permissive for retinal axons, but is specifically nonpermissive for tectobulbar axons, resulting in a strong fasciculation of the latter; and growth cones of temporal retinal axons are reversibly inhibited in their motility by direct contact with the tectobulbar axon's membrane.

\section{Introduction}

A characteristic feature of the vertebrate's and invertebrate's central nervous system is that axons belonging to the same functional class of neurons grow as a fasciculated tract; thus, axons appear to prefer to fasciculate on neurites of their own type rather than on processes of a different pathway (Zipser et al., 1989). As a result, tracts consisting primarily of a homogeneous population of neurons are generated. A behav ior similar to this in vivo phenomenon can be observed in vitro (Bray et al., 1980; Kapfhammer et al., 1986).

More than 100 discrete, long-distance-projecting fiber tracts (cited from Silver et al., 1987), each containing from thousands to millions of axons, are formed during embryonic development. Each of these neuronal pathways is not only homogeneous in its composition, but is also localized within a characteristic and defined region of the central nervous system. Even axons leaving ectopically transplanted grafts form compact tracts at reproducible locations inside the host tissue (for review see Katz et al., 1980; Hankin

\footnotetext{
† Present address: Department of Neurobiology, Stanford University School of Medicine, Stanford, California 94305-5401.
}

and Lund, 1987; Wictorin et al., 1990). On the other hand, mechanical diversion of retinal axons out of their characteristic routes or destruction of their natural environment via enzyme digestion results in a disorientation of axonal growth and the formation of a chaotic fibrous net (Goldberg, 1977; Halfter and Deiss, 1984). These and other findings indicate that at least some of the cues directing the orientation of growth cones are displayed only locally within the direct environment of their normal growth route. Thus, restricted axonal growth within the appropriate environment might be a necessary prerequisite for accurate navigation of growth cones.

During normal embryonic development, pathways are generated within overlapping time periods, i.e., axons belonging to different tracts grow at the same time and in close proximity to each other. Mechanical and/or molecular mechanisms that prevent intermixing of neighboring processes from different pathways are therefore likely to exist. We have investigated the problem of separating axonal pathways during embryonic development using the avian optic tectum (the dorsal part of the mesencephalon) as a model system. On embryonic day 6 (E6) ganglion cell axons originating in the contralateral retina start invading the optic tectum in an anterior to posterior direction (Rager, 1980). They grow as single axons within the most superficial layer and at right angles to a parallel array of highly fasciculated tectobulbar axons (Goldberg, 1974; Kröger and Schwarz, 1990). These tectofugal axons grow from dorsal to ventral within the optic tectum, but change to a posterior direction either shortly before or after having crossed the ventral midline (Kröger and Schwarz, 1990). Afferent retinal axons eventually form the stratum opticum, whereas tectobulbar axons contribute to the stratum album centrale, the main efferent layer of the optic tectum.

Despite the ability of retinal axons to grow in regions of the central nervous system that do not represent their normal target area (Harris, 1986; Hankin and Lund, 1987) and despite a transiently existing population of misrouted retinal axons in vivo (McLoon and Lund, 1982; O'Leary et al., 1983; Halfter and Deiss, 1984; Thanos and Bonhoeffer, 1984; Halfter, 1988), retinal axons have never been reported outside their characteristic lamina while invading the optic tectum. This includes even those retinal axons that grow into a transplanted supernumerary optic tectum (Alvarado-Mallart and Sotelo, 1984). If retinal axons are able to extend into ectopic regions of the central nervous system, what mechanisms normally restrict their growth to the most superficial tectal layer, resulting in the formation of a distinct stratum opticum, and what mechanisms prevent intermixing of tectobulbar and retinal processes? In this study we provide evidence that differences in the interaction of retinal and tectobulbar axons with the extracellular matrix pro- 


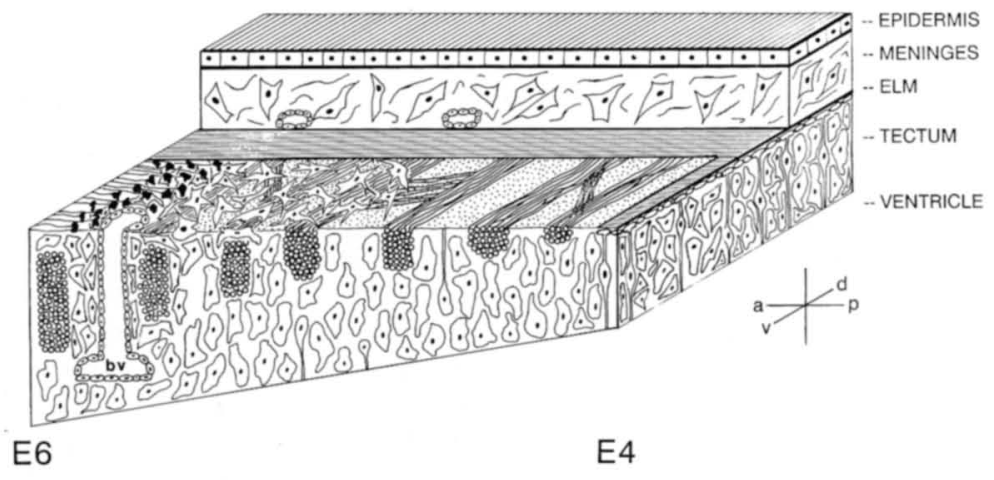

Figure 1. Schematic Representation of the Development of the Optic Tectum between $\mathrm{E} 4$ and $\mathrm{E} 6$

The epidermis, meninges, and external limiting membrane (striped plane), together with the neuroepithelial cell endfeet, were partially removed. The shape of a typical neuroepithelial cell is shown in the front right corner. The tectobulbar axons grow as thick fascicles from dorsal (d) to ventral (v). Frequently small bundles shift from one fascicle to a neighboring fascicle. Retinal axons invade the optic tectum beginning on E6 in an anterior (a) to posterior ( $\mathrm{p}$ ) direction. They grow in the most superficial layer as single, unfasciculated axons and at right angles to the tectobulbar fascicles. Retinal and tectobulbar axons are separated from each other by a thin layer of cells.

ELM, external limiting membrane; bv. blood vessel.

tein laminin and with their direct cellular environment, as well as selective inhibition of growth cone extension, might separate the axons of these two long-distance-projecting fiber pathways.

\section{Results}

The experimental system that was chosen to search for mechanisms which might underlie the separation of two axonal tracts is schematically illustrated in Figure 1. This "four-dimensional" (time and space) reconstruction is based on this as well as on previous investigations (LaVail and Cowan, 1971; Goldberg, 1974; Puelles and Bendala, 1978; Kröger and Schwarz, 1990). Tectobulbar axons growing in a dorsal to ventral direction within the tectum form a parallel array of thick fascicles. During early development, these fascicles are located in the marginal zone subjacent to the external limiting membrane, but separated from the basal lamina by the neuroepithelial cell endfeet ( $S$. Kröger, unpublished data). Beginning on E 5.5, tectobulbar axons are displaced from the most superficial layer deeper into the tissue by cells migrating laterally out of the ventricular proliferative zone (Puelles and Bendala, 1978). On E6 retinal axons start to invade the optic tectum in a posterior direction, beginning at the anterio-ventral pole (Rager, 1980). They grow in the outermost layer at right angles to the underlying tectobulbar fascicles but separated from them by a thin layer of cells.

To examine the exact cellular environment of retinal and tectobulbar axons as well as the spatial relation of the two types of processes to each other, we prepared semithin sections of E5 (Figure 2A) and E7 (Figure 2B) optic tecta. The cell bodies of tectobulbar neurites are large and oval shaped and are located underneath their axonal processes that extend within the marginal zone subjacent to the external limiting membrane (Figure $2 \mathrm{~A}$ ). The ventricle is lined by rapidly dividing neuroepithelial precursor cells, radially oriented between the ventricular and meningeal surface. On E7, tectobulbar axons form the fascicles of the stratum album centrale (Figure 2B) with its typical comb-like appearance. At this later stage, retinal axons are forming the stratum opticum in the anterior (developmentally most advanced) part of the optic tectum (Figure $2 \mathrm{~B}$ ). The two types of processes are closely apposed, separated from each other only by an approximately $20 \mu \mathrm{m}$ thick single cell layer (Figure $2 \mathrm{~B}$, arrows). The cell bodies between the two processes-containing layers constitute a rather loose network and do not appear to form a barrier that would be impenetrable to either retinal or tectobulbar growth cones. Instead, a number of areas without cell bodies between both layers can be observed (Figure 2B, arrowheads). Since we could not observe an apparent mechanical boundary between the two axonal types, we investigated molecular mechanisms that might explain their separation.

\section{Substrate Specificities of Retinal and Tectobulbar Axons}

Culture systems for the growth of retinal and tectobulbar axons on a basal lamina substrate have recently become available (Halfter et al., 1987; Kröger and Schwarz, 1990). This basal lamina preparation is heterogeneous in its composition, containing several different molecules that promote axonal outgrowth (S. Kröger, unpublished data). Therefore, the ability of single purified proteins to promote outgrowth of both retinal and tectobulbar axons was studied. No outgrowth of either type of process is observed on nitrocellulose or glass coated with poly-L-lysine, fibronectin, vitronectin (serum spreading factor), fetal calf serum, heparan sulfate, chondroitin sulfate, or chicken serum (data not shown). Retinal and tectobulbar axons both grow slowly and are highly fasciculated on native collagen from rat tail tendon (data not shown, 

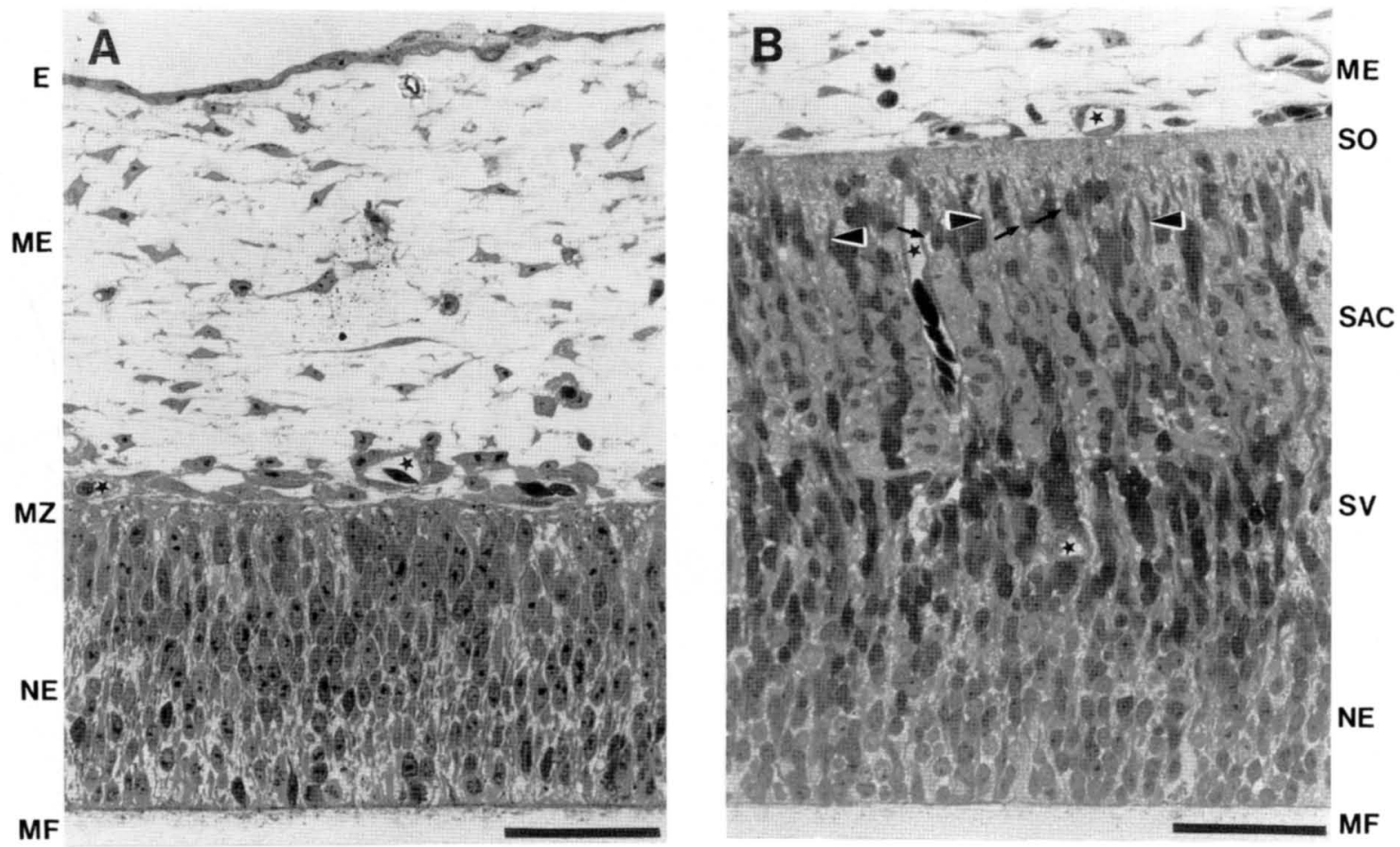

Figure 2. Semithin Section $(4 \mu \mathrm{m})$ through the Wall of the E5 and E7 Optic Tectum

(A) E5 tectum. (B) E7 tectum. The plane of sectioning perpendicular to the tectobulbar fascicles and parallel to the retinal axons was chosen. The arrows in $(B)$ indicate cell bodies localized between the retinal axon-containing stratum opticum and the tectobulbar axoncontaining stratum album centrale. Arrowheads point at spaces devoid of cell bodies between the two layers. Blood vessels penetrating the neural tissue from the overlying leptomeninges are marked with asterisks.

$E$, epidermis; ME, meninges; MZ, mantle zone; NE, neuroepithelial cells; MF, membrane filter; SO, stratum opticum; SAC, stratum album centrale; SV, subventricular zone. Bars, $200 \mu \mathrm{m}$.

but see Halfter et al., 1983; Kröger and Schwarz, 1990). A major difference between the two types of axons is observed when laminin-coated surfaces are used. In contrast to retinal explants, which show vigorous extension of neurites with a speed of approximately 71 $\pm 10 \mu \mathrm{m} / \mathrm{hr}$ (mean $\pm \mathrm{SD}, \mathrm{N}=5$ ), tectobulbar axons are not able to use the same laminin-coated surfaces as a substrate (Figure 3). Although explant stripes from the tectum attach firmly to the laminin substrate, processes longer than short stumps are never observed even after prolonged culture periods. This is independent of the laminin concentration used for coating (5-150 $\mu \mathrm{g} / \mathrm{ml}$; optimal concentration for retinal axons is $100 \mu \mathrm{g} / \mathrm{ml}$ ) and of the surface to which the laminin is bound (acid-washed glass, poly-L-lysine-precoated glass or plastic, or nitrocellulose). The inability of tectobulbar axons to extend on laminin might indicate a lack of the appropriate receptor for this extracellular matrix molecule on their surface.

We next investigated growth of tectobulbar axons on affinity-purified G4 protein (Rathjen et al., 1987), since previous investigations have shown that G4 is expressed on tectobulbar axons in vivo and in vitro (Kröger and Schwarz, 1990). Retinal axons, whose ability to extend on G4 has already been described (Lagen- aur and Lemmon, 1987), were used as controls. As shown in Figure 4, G4 is an excellent substrate for both retinal and tectobulbar axons. Retinal axons extend on G4 and on the basal lamina at a growth rate of approximately $80 \pm 11 \mu \mathrm{m} / \mathrm{hr}$ (mean $\pm \mathrm{SD}, \mathrm{N}=4$ ), and tectobulbar axons grow at a speed of $40 \pm 7 \mu \mathrm{m} /$ hr (mean $\pm \mathrm{SD}, \mathrm{N}=4$ ) on both substrates. While retinal axons grow unfasciculated on the basal lamina as well as on G4, tectobulbar axons form bundles on the basal lamina but grow as single axons on G4-coated nitrocellulose, indicating that tectobulbar axons might have a higher affinity for $\mathrm{G} 4$ than for the basal lamina.

\section{Permissive and Nonpermissive Environment for Retinal and Tectobulbar Axons in the Optic Tectum}

To study the interaction of retinal and tectobulbar axons with their immediate cellular and extracellular environment, we used a recently characterized preparation of the tectal basement membrane as a substrate for the two types of processes (Kröger and Niehörster, 1990). This basement membrane separates the neural optic tectum from the overlying mesenchymal stroma and is covered after isolation on its surface by a carpet 


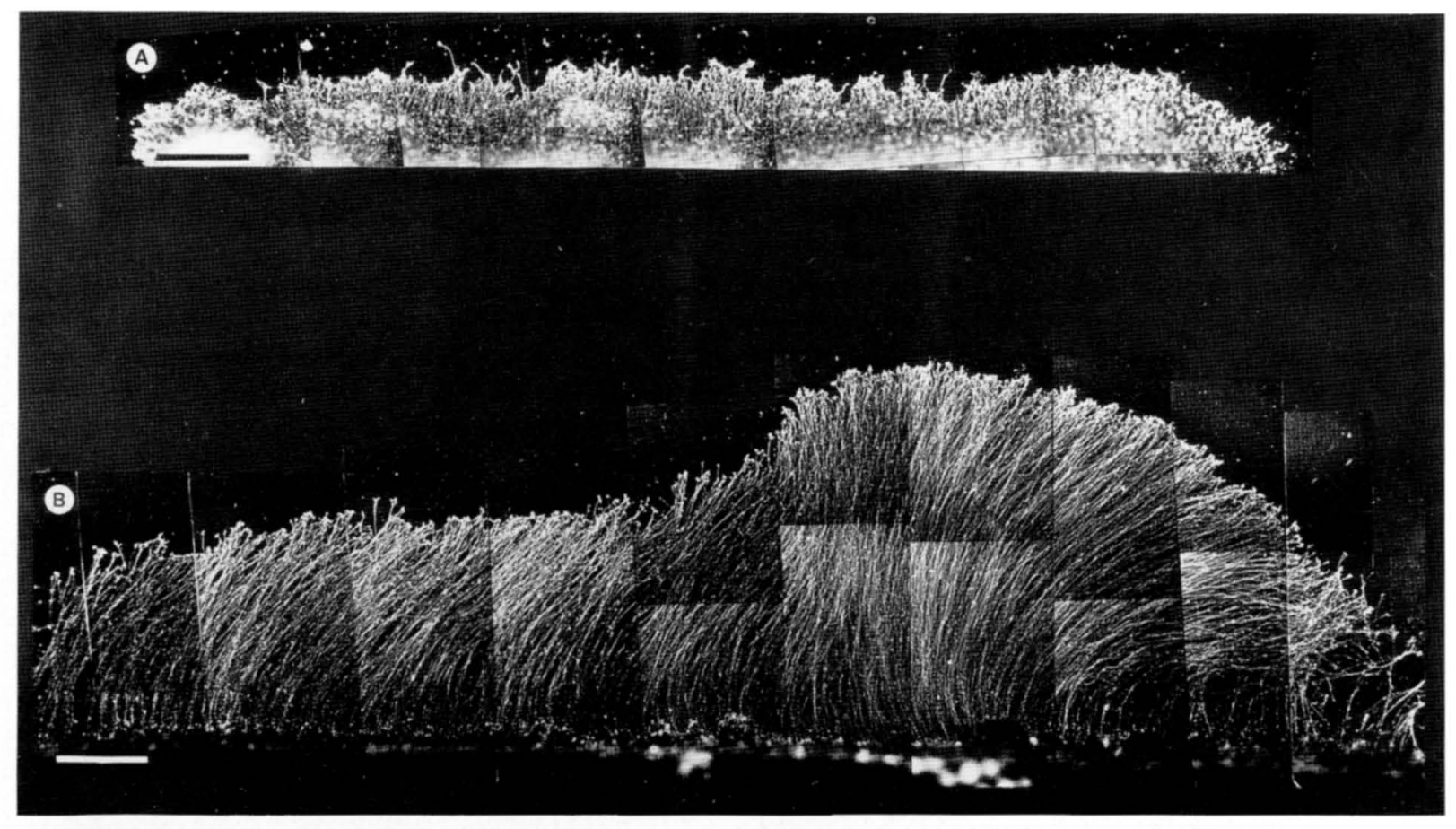

Ficure 3. Cuiture of Tectobulbar and Retinal Explant Stripes on Coverslips Coated with Purified Laminin

(A) rectobulbular explant. (B) Retinal explant. The explant stripes are located on the bottom of each montage. While retinal axons show visurous extension of neurites on the substrate, tectobulbar axons are not able to grow on an identically prepared surface even after prolonged culture periods. For better visualization, axons were stained with the Q211 antibody and an FITC-labeled secondary antibody. Culture time: (A) 96 hr; (B) $24 \mathrm{hr}$. Bars, $400 \mu \mathrm{m}$.

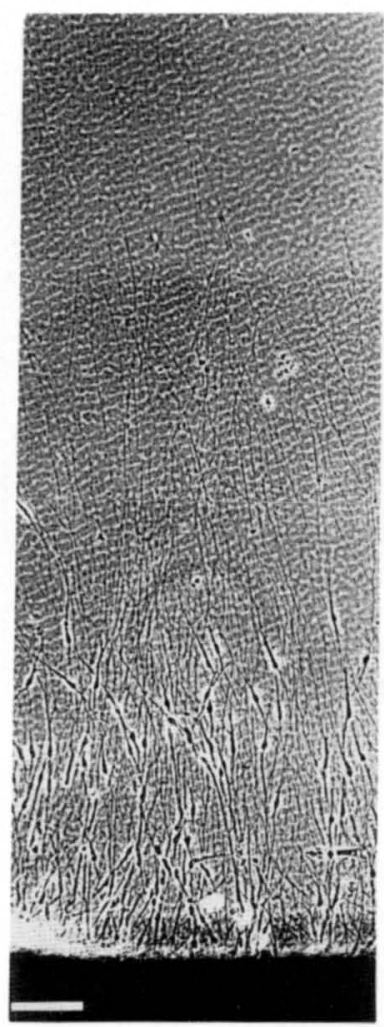

A

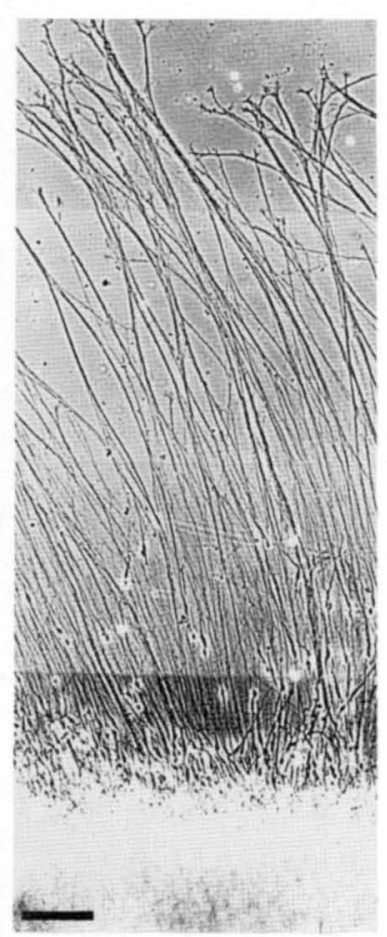

B

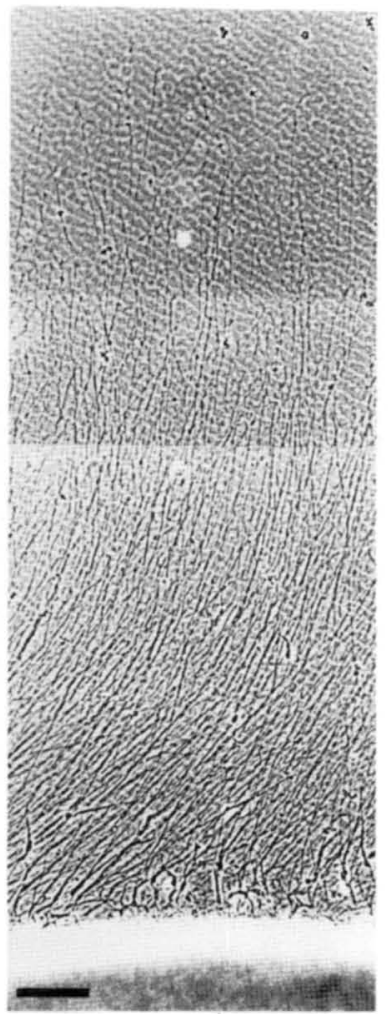

C

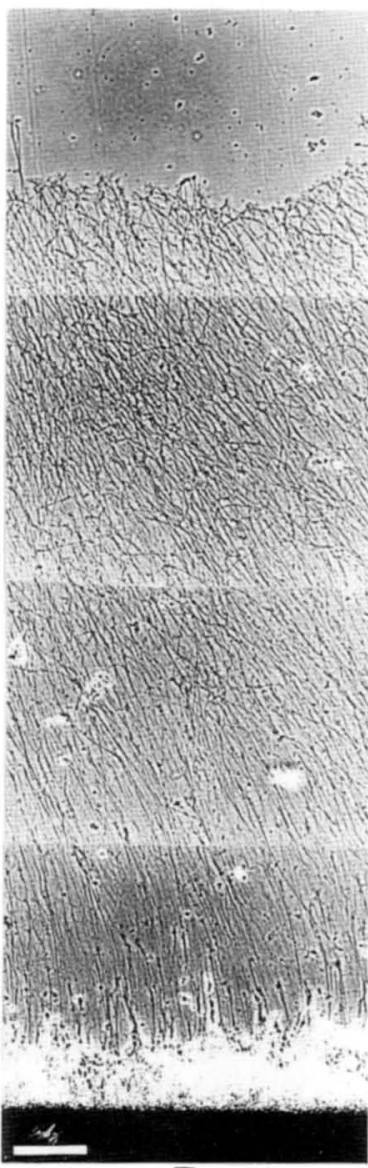

D

Figure 4. Growth of Tectobulbar and Retinal Axons on Affinity-Purified G4 Bound to Nitrocellulose and on E8 Retinal Basal Lamina ( $A$ and $B$ ) Tectobulbar axons; (C and D) retinal axons. ( $A$ and $C$ ) G4 bound to nitrocellulose; ( $B$ and $D)$ retinal basal lamina. Note the difference in fasciculation of tectobulbar axons on G4 (A) and on the basal lamina (B). The "wavy" background in (A) and (C) is due to a shrinkage of the nitrocellulose during the fixation procedure.

Incubation period: (A and B) $40 \mathrm{hr}$; (C and D) $18 \mathrm{hr}$. Bars, $100 \mu \mathrm{m}$. 


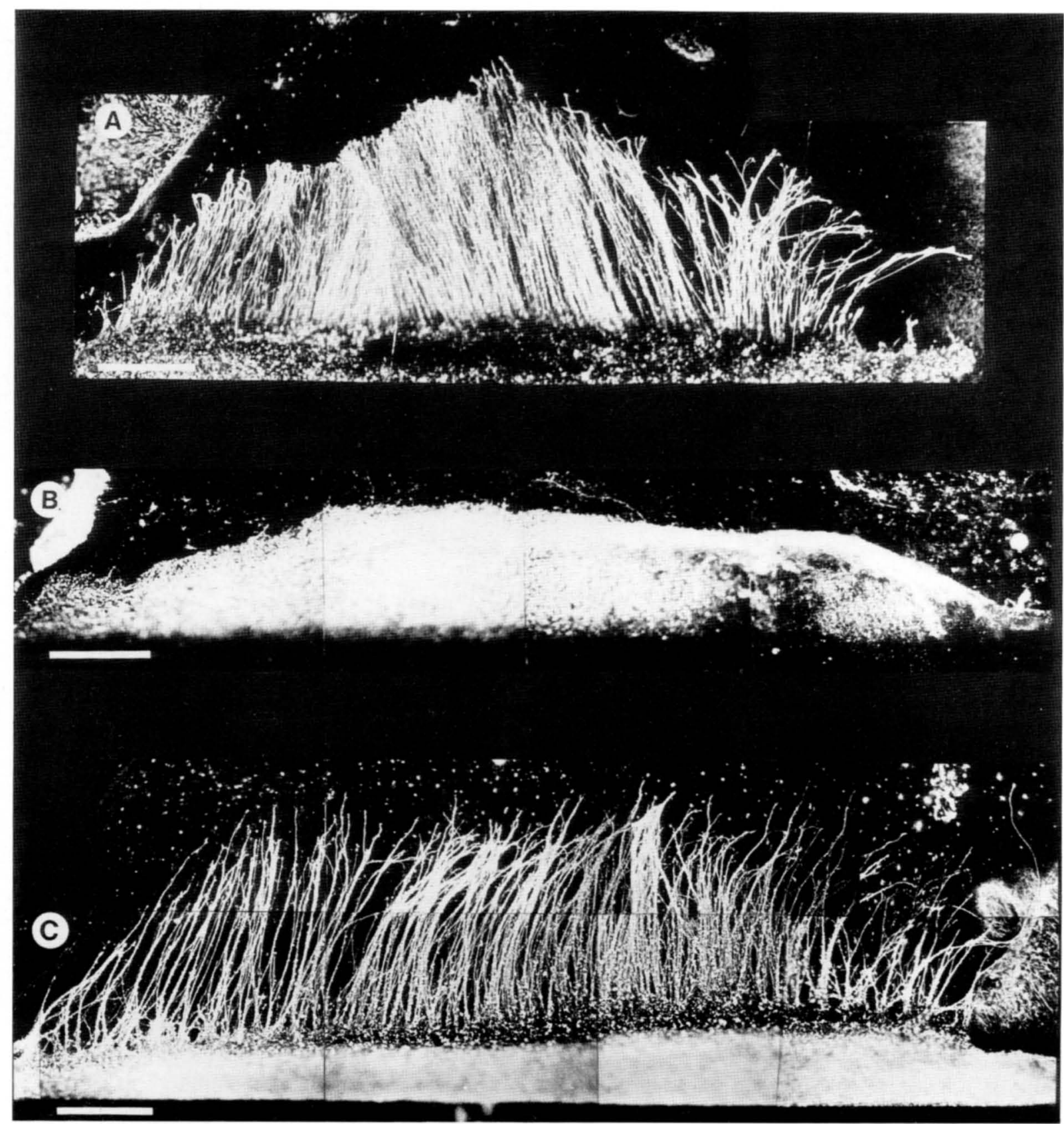

Figure 5. Growth of Retinal and Tectobulbar Axons on the External Limiting Membrane of E5 Optic Tecta

The basement membrane with the neuroepithelial cell endfeet attached is an excellent substrate for retinal axons (A). In contrast, tectobulbar axons cannot grow on identical preparations (B), but can after the endfeet have been removed with detergent or hypoosmotic shock prior to explantation (C).

Incubation period: (A) $20 \mathrm{hr}$; (B and C) $40 \mathrm{hr}$. Bars, $400 \mu \mathrm{m}$.

of neuroepithelial cell endfeet, which can be removed by detergent treatment or hypo-osmotic shock (Kröger and Niehörster, 1990). In the 55 embryo the endfeet of neuroepithelial cells represent the direct environment of tectobulbar axons, whereas at stages later than E7, retinal axons have been shown to grow in direct contact with the endfeet (Vanselow et al., 1989). When flat-mounted on a piece of nitrocellulose, this basement membrane preparation, with and without the endfeet, is an excellent substrate for axons from the central and peripheral nervous systems, as well as for neural crest cell migration (Kröger and Niehörster, 1990). We have used this preparation for culturing retinal and tectobulbar axons. While retinal axons grow excellently on the $E 5$ basement membrane preparation with and without the endfeet (Figure $5 \mathrm{~A}$ ), tectobulbar axons do not extend processes on the same kind of preparation (Figure 5B), unless the endfeet 

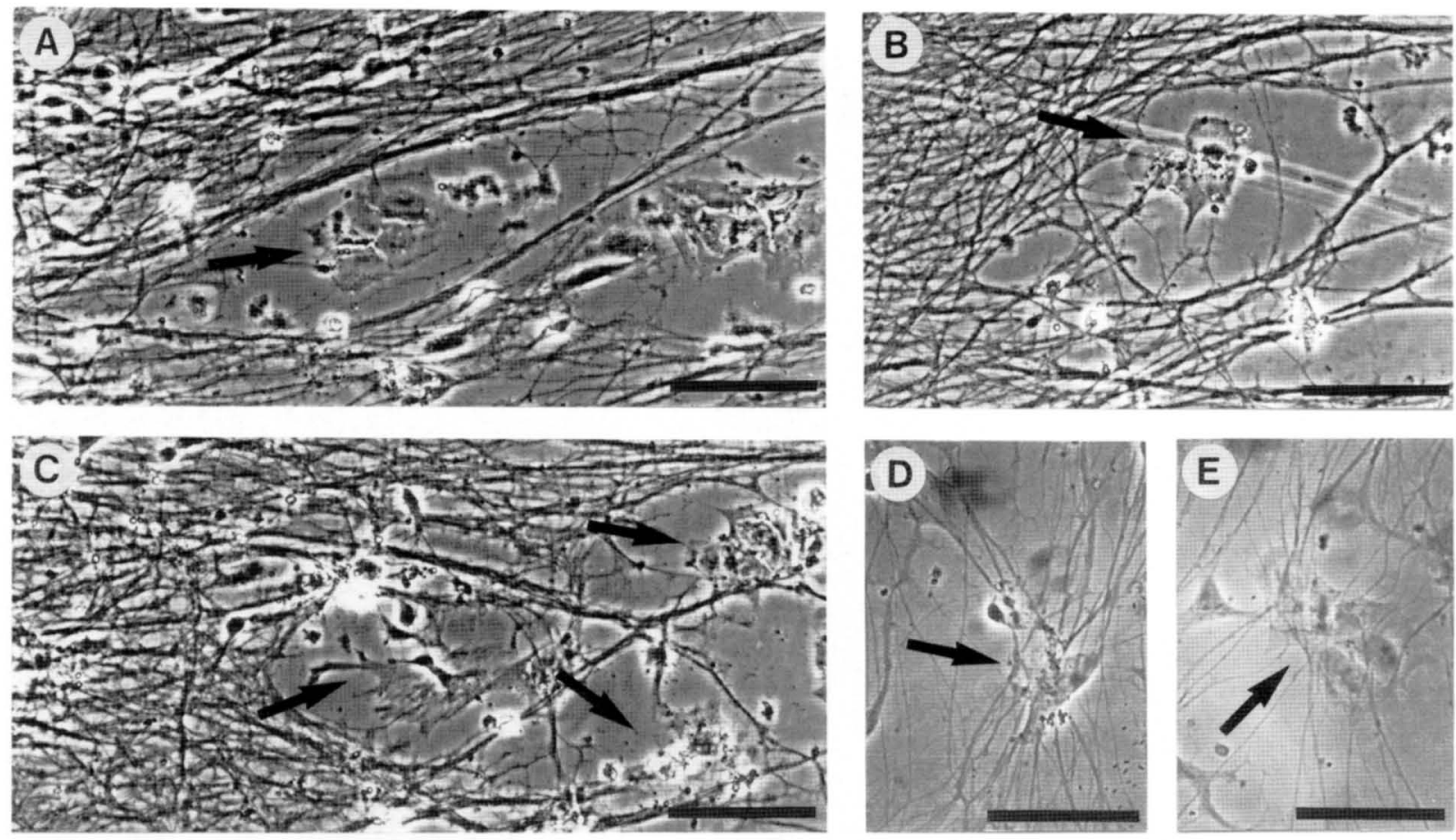

Figure 6. Coculture of Tectobulbar and Retinal Axons with Neuroepithelial Cells Isolated from E3 Optic Tecta

Tectobulbar axons (A-C) avoid the neuroepithelial cells (arrows). The processes form a ring at a distance around the flat cells. In contrast, the same neuroepithelial cells represent a favorable substrate for retinal axons, indicated by several processes on top of the neuroepithelial cells (D and $E$ ).

Bars, $100 \mu \mathrm{m}$.

have been removed with detergent or distilled water prior to explantation (Figure 5C).

While the endfeet-containing basement membrane preparations from E5 and E8 optic tecta do not promote outgrowth of tectobulbar axons, basement membranes from E12 and from older embryos have the ability to serve as a substrate for tectobulbar axons even with the endfeet still attached (data not shown). Tectobulbar axons grow on the basal lamina prepared from the embryonic chick retina even when the endfeet have not been removed and irrespective of the embryonic age of the basal lamina (Kröger and Schwarz, 1990). These results suggest that the tectal neuroepithelial cell endfeet might render the E5 and E8 tectal basement membrane specifically nonpermissive for tectobulbar axons, whereas the endfeet of older preparations have no influence on the same axons.

To confirm the results obtained with the endfeetcontaining basement membrane, we examined the interaction of retinal and tectobulbar axons with intact neuroepithelial cells by preparing cocultures of retinal and tectobulbar neurons with retinal and tectal neuroepithelial cells. Tectobulbar axons avoid neuroepithelial cells from the tectum (Figures $6 \mathrm{~A}-6 \mathrm{C}$ ). They grow around these cells, leaving holes within the mat of axons. In contrast, tectobulbar axons do not avoid neuroepithelial cells from the retina (data not shown). Growth of retinal axons is not impaired by neuroepithelial cells of both origins; instead they seem to be a rather attractive surface for the axons to grow on (Figures 6D and 6E). Accordingly, confluent monolayers of neuroepithelial cells from E5 optic tecta support axonal outgrowth from retinal explants, whereas no tectobulbar neurites are observed extending from the tectal explants (data not shown). These data again indicate that neuroepithelial cells from the early optic tectum are specifically nonpermissive for tectobulbar axons.

In addition to intact cells, we tested the substrate properties of isolated tectal cell membranes. Cytoplasmic membranes from the optic tectum of all embryonic ages have previously been shown to be a good substrate for retinal axons when bound as a carpet to Nuclepore filters (Walter et al., 1987). In contrast, E5 tectal membranes do not promote outgrowth of tectobulbar axons, whereas membranes from E16 optic tecta, isolated in parallel, can serve as a substrate (data not shown). If membranes prepared from 5- and 16-dold optic tecta are arranged as a carpet consisting of alternating stripes, then tectobulbar axons remain confined to the lanes of E16 membranes (Figures 7A and $7 \mathrm{~B}$ ). Retinal axons grow excellently on E5 and E16 membranes, and when given the choice between alternating membrane preparations they show only a slight preference for the E16 stripes (data not shown). This is indicated by a slightly higher density of the axons on the E16 membrane stripes compared with the E5 membranes. Thus, neuroepithelial cells of the 

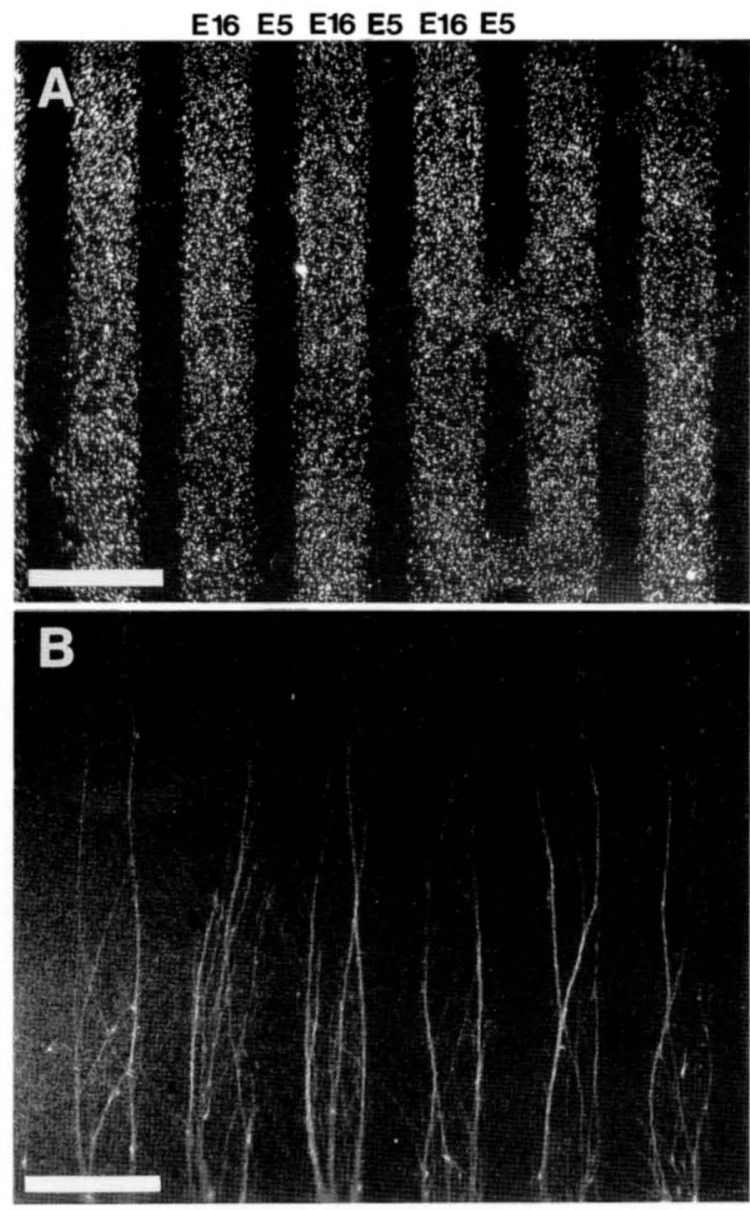

Figure 7. Growth Pattern of Tectobulbar Axons on Carpets Consisting of Alternating Stripes of Isolated Cytoplasmic Membranes from E5 and E16 Optic Tecta

(A) FITC fluorescence of beads that were added to the E16 membranes. The E.5 membranes were not labeled and fill the space between the E16 membranes. Adding the beads to the $\mathrm{E} 5 \mathrm{mem}$ branes had no detectable influence on the preferred growth of tectobulbar axons on the E16 membranes. (B) RITC fluorescence of the same field as depicted in (A), showing the tectobulbar axons. Staining of the axons was achieved by placing a piece of RITC-agarose on top of the optic tectum prior to explantation, as described in Experimental Procedures. Axonal growth is confined to the E16 membrane carpets.

Culture time: $\mathbf{4 8} \mathrm{hr}$. Bars, $200 \mu \mathrm{m}$.

optic tectum appear to be specifically nonpermissive for tectobulbar axonal extension in vitro.

\section{Selective Contact-Mediated Inhibition of Temporal Retinal Growth Cones by Tectobulbar Axons}

To study the direct interactions of retinal and tectobulbar axons with each other, we explanted both types of processes from defined regions of the retina and optic tectum, respectively, in close proximity to each other. These cocultures show that outgrowing processes of both types of axons usually intermix or even cofasciculate. Only temporal retinal axons segregate from tectobulbar axons. When cocultured with tectobulbar axons, temporal retinal axons form dis- tinct and apparently separate territories (data not shown). Video time-lapse techniques were applied to examine the behavior of individual identified growth cones contacting different types of axons. Growth cones from a nasal retinal explant cross a tectobulbar axon without retardation and without a change in morphology (Figures 8A-8F). The same behavior is observed when a tectobulbar growth cone meets a nasal or a temporal retinal axon (data not shown). If a tectobulbar growth cone encounters a tectobulbar axon, it frequently joins the contacted neurite and fasciculates with it, indicating a preference of the growth cone for the neural surface compared with the underlying basal lamina substrate. In contrast to the behavior of nasal retinal or tectobulbar growth cones, temporal retinal growth cones collapse when encountering a tectobulbar axon (Figures 8G-8L). Within a few minutes after direct contact, lamellipodia and filopodia retract and the size of the growth cone shrinks. Bends proximal to the growth cone are often observed (Figure 8I, arrowheads). The growth cone of the contacted axon does not show any morphological changes. Approximately $15 \mathrm{~min}$ after the initial contact, the retinal growth cone is almost completely resorbed and, with the exception of a few retraction fibers (Figure 8J, arrowheads), adhesion to the underlying substrate appears to be lost. After a short pause of 10-25 $\mathrm{min}$, a new growth cone is generated at the point to which the main body of the axon had retracted (Figure 8K). This new growth cone either tries again to cross the tectobulbar axon or continues to grow at an oblique angle to the formerly contacted neurite (Figure $8 \mathrm{~L}$ ). Usually the second crossing attempt is accompanied by another collapse, but at the third encounter the growth cone often succeeds in crossing the axon. We have investigated the behavior of identified growth cones in all combinations of nasal and temporal retinal axons with each other and with tectobulbar axons from the anterior and posterior part of the optic tectum. Table 1 shows a summary of the results obtained. Nasal retinal growth cones do not collapse on encountering another nasal or temporal retinal axon, in agreement with data recently published (Raper and Grunewald, 1990). A collapse is observed only when temporal retinal growth cones encounter tectobulbar axons. Thus, tectobulbar axons can selectively inhibit the motility of temporal retinal growth cones by a contact-mediated process.

\section{Discussion}

Retinal and tectobulbar axons form an orthogonal network of processes that grow at the same time and in close proximity to each other, thus providing an experimental system to investigate the mechanisms that might underlie the separation of two different long-distance-projecting fiber pathways. One mechanism might be a mechanical barrier. For example, in a different part of the visual system, an axonal refractory boundary called a "knot" (Silver, 1984) has been de- 

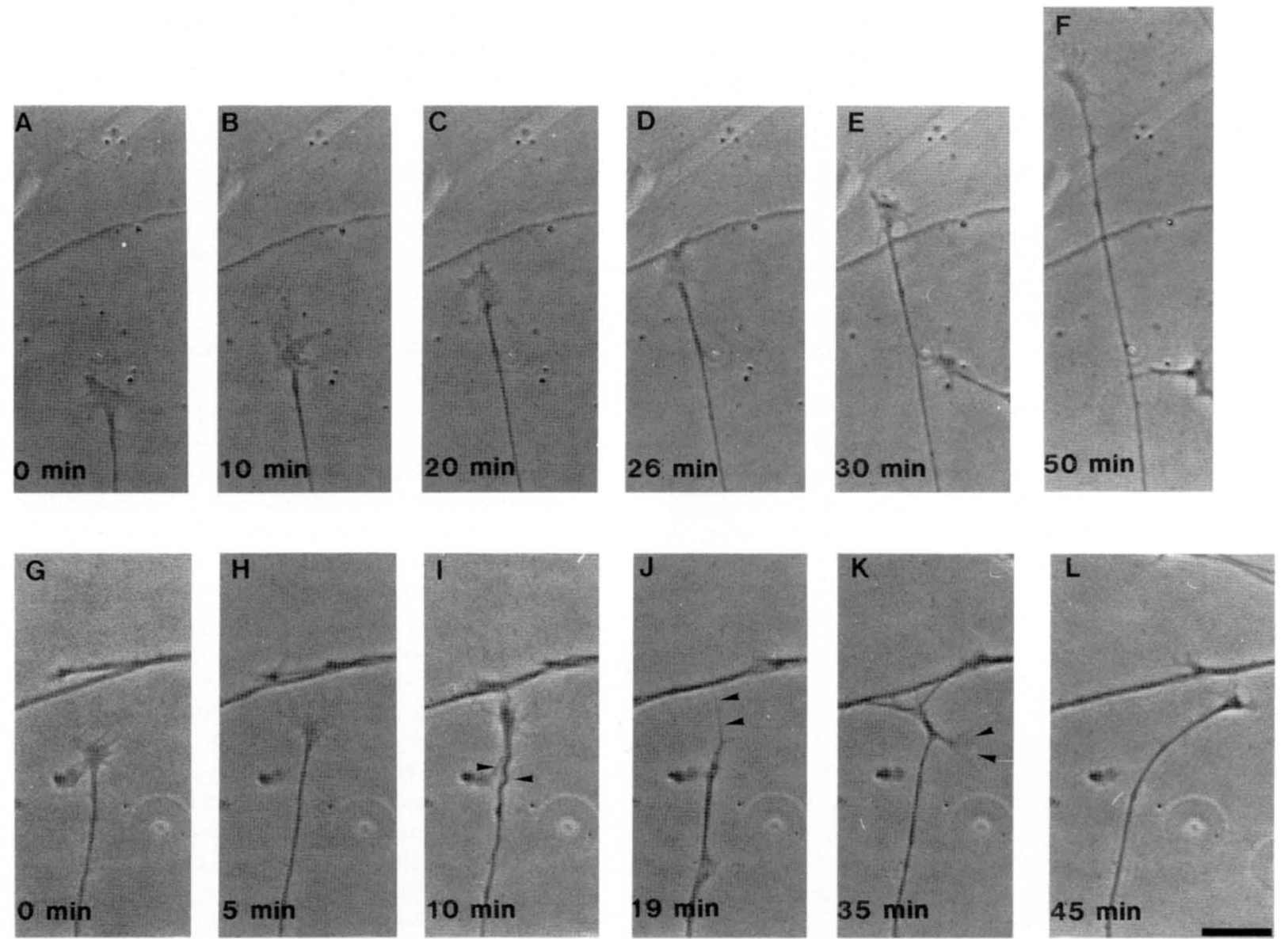

Figure 8. Behavior of a Nasal and a Temporal Retinal Growth Cone When Encountering a Tectobulbar Axon

The relative time in minutes is indicated on the lower left of each picture. While the nasal growth cone crosses the tectobulbar neurite without any obvious change in speed or morphology (A-F), the temporal growth cone collapses and retracts reversibly (G-L). In the example shown, the reformed growth cone resumes growth at an oblique angle to the former contacted neurite. In other cases it tried to cross the neurite several times, eventually succeeding.

Bars, $20 \mu \mathrm{m}$.

scribed to be a barrier for growth cones. This structure, composed of specialized neuroepithelial cells, is located at the diencephalic-telencephalic junction near the chiasm in mouse and chick embryos (Silver, 1984; Silver et al., 1987). As a result of its lack of large extracellular spaces and the relative absence of the adhesion molecule N-CAM in this region, this structure has been implicated in the segregation of the optic and the olfactory sensory tracts during embryonic development (Silver et al., 1987). However, axons of the retinal and tectobulbar fiber tracts are separated from each other only by an approximately $20 \mu \mathrm{m}$ wide layer of single cells. Judged from their location, the time of their appearance, and their morphology these cells probably represent "freely migrating type II neuroblasts" (Puelles and Bendala, 1978), which have migrated radially from their site of origin in the ventricular proliferation zone. Eventually these cells will form the various types of interneurons of the tectal plate (Puelles and Bendala, 1978). The layer of cells separating retinal and tectobulbar axons does not ap-

\begin{tabular}{|c|c|c|c|}
\hline \multicolumn{2}{|l|}{ Combination } & \multicolumn{2}{|c|}{ Collapse $^{a}$} \\
\hline Growth Cone & Axon & Yes & No \\
\hline $\mathrm{T}$ & $\mathrm{p}$ & 17 & $1(5)$ \\
\hline$T$ & a & 24 & $3(6)$ \\
\hline$N$ & $\mathrm{p}$ & 2 & $9(3)$ \\
\hline$N$ & $\mathrm{a}$ & 0 & $9(2)$ \\
\hline$p$ & $\mathrm{~T}$ & 1 & $16(4)$ \\
\hline$p$ & $\mathrm{~N}$ & 1 & $8(2)$ \\
\hline a & $\mathrm{T}$ & 0 & $14(5)$ \\
\hline a & $N$ & 0 & $9(2)$ \\
\hline a & $\mathrm{a}$ & 0 & $3(2)$ \\
\hline$p$ & $\mathrm{p}$ & 0 & $14(4)$ \\
\hline $\mathbf{T}$ & $\mathrm{T}$ & 0 & $18(7)$ \\
\hline$N$ & $N$ & 1 & $12(6)$ \\
\hline
\end{tabular}

T and $\mathrm{N}$ : temporal and nasal retinal neurite. $\mathrm{a}$ and $\mathrm{p}$ : anterior and posterior tectobulbar neurite.

${ }^{a}$ For each observation, only the first encounter of the growth cone with an axon was scored. The values in parentheses indicate the number of explant pairs on which these observations were made. 
pear tight enough to prevent growth cone penetration between these two pathways. Moreover, N-CAM immunoreactivity appears to be continuous between the two layers (Kröger and Schwarz, 1990). Thus, we conclude that a mechanical barrier similar to that in the knot region is not likely to explain the separation of the two axonal pathways in the optic tectum, although we cannot completely exclude mechanical influences of the tectal tissue. It also remains to be determined whether various N-CAM forms, differentially distributed, might mediate separation of retinotectal and tectobulbar axons via a "modulated adhesivity" (Edelmann, 1983).

Since an obvious physical or mechanical obstacle between the retinotectal and tectobulbar pathway appears to be absent, other mechanisms must account for the effective separation of these two types of processes. Evidence for three principal mechanisms, all based on molecular differences between the two axonal populations is presented in this study.

\section{Substrate Specificity of Retinal and Tectobulbar Axons}

The first mechanism is based on the substrate preferences of the two axonal populations. Retinal and tectobulbar axons differ in their ability to extend on surfaces coated with purified laminin. Laminin is a high molecular weight extracellular matrix glycoprotein and is assumed to be the natural substrate for several developing vertebrate central nervous system axons (for review see Sanes, 1989). Retinal axons grow very well on surfaces coated with laminin (Rogers et al., 1983; Adler et al., 1984; Smalheiser et al., 1984; Tomaselli et al., 1988). On the other hand, tectobulbar axons are not able to use this protein for axonal extension, indicating that they do not express the appropriate receptor on their surface. In the avian embryonic visual system, i.e., the retina, optic nerve, chiasm, optic tract, and tectum, as well as in the mesencephalic tegmentum of embryonic mice, laminin is exclusively localized around the endfeet of the neuroepithelial cells and the overlying basement membrane (Halfter and Fua, 1987; Cohen et al., 1987; Letourneau et al., 1988; Liesi and Silver, 1988; Kröger and Niehörster, 1990). Staining of neuroepithelial cells for laminin always results in a punctate appearance of the immunoreactivity on the endfeet, but not on the rest of these palisade-like cells. Evidence from several studies suggests that growing axons can detect substrates of differing adhesivity and, when given the choice, will preferentially grow on the more adhesive substrate (see, for example, Letourneau, 1975). Thus, a restricted distribution of an adhesive molecule might guide an axon to grow on a particular course. In the optic tectum laminin could define a preformed substrate pathway (Katz et al., 1980) favorable for retinal axons but not supportive for tectobulbar axons, which would accordingly be confined to deeper layers of the optic tectum.

\section{Influence of Neuroepithelial Cells on Retinal and Tectobulbar Axons}

A second mechanism dealing with the segregation of retinal and tectobulbar axons involves the interaction of the two types of processes with cells of their immediate tectal environment. Three independent lines of evidence indicate that neuroepithelial cells in the optic tectum are selectively not favorable for tectobulbar axons: neuroepithelial cells are avoided by tectobulbar axons in cocultures; the tectal external limiting membrane, which is covered on its surface by a carpet of endfeet from the same neuroepithelial cells (Kröger and Niehörster, 1990), cannot serve as a substrate for tectobulbar axonal growth unless the endfeet have been removed prior to explantation; and tectobulbar axons cannot grow on a carpet of cytoplasmic membranes prepared from E5 optic tectum. We consider this nonpermissiveness specific, since retinal axons are never influenced in any of these experiments, i.e., retinal axons do not avoid tectal neuroepithelial cells in cocultures, they can grow on the external limiting membrane even when the endfeet are still attached (Kröger and Niehörster, 1990), and they are able to extend processes on a carpet of 55 tectal membranes (Walter et al., 1987). Furthermore, neuroepithelial endfeet, which cover the retinal basal lamina (Halfter et al., 1987), do not influence growth of tectobulbar axons (Kröger and Schwarz, 1990). An additional indication of specificity is the fact that the nonpermissiveness is lost at later stages of development, i.e., the external limiting membrane and cell membranes prepared from developmentally older optic tecta (E16) both represent a good substrate for tectobulbar axons. The transition of nonpermissive to permissive occurs around E10, coinciding with the period when primitive neuroepithelial cells differentiate into glia cells. This differentiation process is accompanied by a change in the size and density of the endfeet (Vanselow et al., 1989; Kröger and Niehörster, 1990) and by the appearance of R-5 immunoreactivity (detecting a vimentin-like protein in these cells; Vanselow et al., 1989) and other biochemical glial cell markers like glutamine synthetase (Linser and Perkins, 1987). It is conceivable that these changes reflect the differentiation of neuroepithelial cells to radial glial cells and that this differentiation might be accompanied by a loss of the nonpermissiveness.

Attempts to distinguish clearly between passive lack of growth-permissive molecules, inhibition, and active repulsion of tectobulbar axons by neuroepithelial cells have not been successful and await further experimental work. At the moment we cannot decide, for example, whether tectobulbar axons do not grow on the E5 tectal basement membrane because the endfeet physically block the access of growth cones to the extracellular matrix substrate in the basement membrane, or whether the endfeet actively inhibit axonal extension. In any case, retinal axons do not appear to be influenced by tectal neuroepithelial cells, hence the effect is specific for tectobulbar ax- 
ons. Therefore, the latter are selectively forced to grow on themselves as a consequence of the nonpermissiveness of the cells in their environment. This might explain the formation of the prominent fasciculated array of tectobulbar axons, their most characteristic feature observed in the optic tectum (Kröger and Schwarz, 1990). The nonpermissiveness of the direct environment would also prevent tectobulbar axons from leaving their fascicles and mixing with retinal axons growing in the overlying stratum opticum.

Preferential growth of tectobulbar axons along each other requires the expression of a substrate molecule on the surface of the axons. One possible candidate is $\mathrm{G4}$, which has been shown to be present on tectobulbar axons in vivo and in vitro (Kröger and Schwarz, 1990) and which can be used as a substrate for elongation by tectobulbar axons. When tectobulbar axons grow on G4-coated nitrocellulose they do so as unfasciculated single axons. This shows the high substrate quality of $\mathrm{G} 4$ and indicates a strong adhesion in vitro of the axon to this substrate compared with the surface of homologous axons.

Since outgrowth of tectobulbar axons is also observed on the cell-free basal lamina prepared from the embryonic retina (Halfter et al., 1987) or the optic tectum (Kröger and Niehörster, 1990), neither of which contains $\mathrm{G} 4$, it is necessary to postulate the existence of an additional substrate molecule from the extracellular matrix. This extracellular component could also be the substrate for the first "pioneering" tectobulbar axons that appear in the optic tectum, since they grow as single processes without direct contact to other neurites (Kröger and Schwarz, 1990). The presence of multiple receptors for different substrate molecules on one axon is in agreement with previous investigations which have shown that more than one component has to be blocked to inhibit outgrowth completely on complex physiological substrates (Bixby et al., 1987, 1988; Tomaselli et al., 1988).

\section{Inhibition of Retinal Growth Cone Motility by Tectobulbar Axons}

The third mechanism that might be involved in the separation of the retinotectal and tectobulbar pathways is the reversible contact-mediated growth inhibition of temporal retinal growth cones by tectobulbar axons. The short distance between the retinal and tectobulbar pathway is in the range of the filopodial length, making physical contact between both axon types at least possible. If temporal retinal axons invading the optic tectum leave the most superficial stratum opticum and penetrate deeper into the tissue, their growth cones would necessarily encounter the tectobulbar fascicles. This would result in a reversible collapse of the growth cone and thus force the growth cone to continue axonal elongation in a more superficial layer. The spatial and temporal morphological changes of the collapse observed in this study are very much reminiscent of those described by Kapfhammer and Raper (1987a, 1987b), who investigated the interaction between growth cones and neurites from sympathetic, ciliary, and dorsal root ganglia as well as from retina and diencephalon. The similarity suggests that a related mechanism might account for the collapse in ours and their investigation. Since the inhibitory component remains to be identified, it is not known whether the effectors in both systems share characteristics. We could not detect a collapse prior to contact of the growth cone with the neurite; growth cones passing very near an axon showed no morphological changes. Thus, it seems likely that the active agent is membrane associated and not a diffusible substance like, for example, a neurotransmitter, as has been shown in several other studies (Haydon et al., 1984; McCobb et al., 1988; Mattson et al., 1988).

The inhibition of neurite elongation is specific for growth cones from the temporal retinal half. Temporal retinal axons have been shown previously to be intrinsically different in several aspects from axons of the nasal retina (Halfter et al., 1981; Bonhoeffer and Huf, 1982, 1985; Walter et al., 1987; Boxberg et al., 1990; Raper and Grunewald, 1990). The reasons for the differences detected in vitro are unknown, but it is possible that the collapsing behavior is modulated by the direct environment of the retinal growth cones in the optic tectum and that in this in vivo environment nasal growth cones might be more sensitive to a repellent component. In this case the differences between nasal and temporal retinal axons would reflect the limitations of the in vitro test systems. In addition, temporal axons topologically terminate in the developmentally most advanced, anterior region of the optic tectum. Since the development of the mesencephalon is faster than its invasion by optic axons, by the time nasal axons arrive at the posterior tectal half (their topological projection site), a tectal plate has already formed. This increases the spatial distance between retinotectal and tectobulbar axons, making a direct contact between nasal axons and tectobulbar fascicles less likely.

It is likely that other (even more important) mechanisms contribute to the separation of axonal tracts, since almost certainly not all of the extracellular matrix and cell surface molecules that might be involved in this process have been discovered. On the other hand, all three mechanisms in concert are sufficient to explain the separation of these two long-distanceprojecting fiber pathways during embryonic development of the avian optic tectum. In addition, the molecular mechanisms described in this report could also be applied to other areas of the central nervous system, like the spinal cord, where numerous axons from several different ascending or descending pathways have to be bundled into specific, characteristically localized tracts and have to be prevented from intermixing. Restricted growth of retinal and tectobulbar axons only within defined layers of the optic tectum might be a necessary prerequisite for the establish- 
ment of the orthogonal directionality and the accurate pathfinding leading to the topographic organization of the retinotectal and tectobulbar projections.

\section{Experimental Procedures}

\section{Materials}

Embryos were obtained from fertilized White Leghorn eggs cultured in a humidified standard egg incubator at $37^{\circ} \mathrm{C}$. The age of the embryos was recorded by days of incubation. Exact staging was performed when necessary according to the criteria of Hamburger and Hamilton (1951). The nomenclature of the six major laminae of the mesencephaion was adopted from LaVail and Cowan (1971). Since the optic tectum develops in a wellcharacterized anterior to posterior gradient, the developmentally most advanced anterior part was chosen for all experiments unless indicated otherwise.

\section{Histology}

For semithin sections, tecta were dissected out of the embryo, fixed in $2.5 \%$ glutaraldehyde, $2 \%$ paraformaldehyde in $0.1 \mathrm{M}$ sodium cacodylate buffer (pH 7.2), postfixed in $1 \%$ osmium tetroxide, dehydrated in alcohol, and embedded in EPON (Roth, Karlsruhe, Germany). Sections were cut at $4 \mu \mathrm{m}$ with a Pyramitome (LKB), mounted on poly-L-lysine-coated slides, and stained with azur-II-methylene blue.

\section{Explant Cultures}

Explants of E6 retinas and E5 tecta were obtained as described previously (Halfter et al., 1983; Kröger and Schwarz, 1990). They were placed with the axon-bearing layer facing the substrate. After an attachment time that varied between $\mathbf{3 0}$ min (basal lamina) and $60 \mathrm{~min}$ (isolated proteins), depending on the substrate, medium consisting of F12 medium (GIBCO) supplemented with $10 \%$ fetal calf serum, $2 \%$ chicken serum, glutamine $(2 \mathrm{mM})$, penicillin $(10 \mu \mathrm{g} / \mathrm{ml})$, streptomycin $(10 \mu \mathrm{g} / \mathrm{ml})$, and $0.4 \%$ methylcellulose (as described by Walter et al. [1987]) was carefully added. Tissues were incubated at $37^{\circ} \mathrm{C}$ and $4 \% \mathrm{CO}_{2}$. For better visualization, axons were stained with the Q211 antibody (Rösner et al., 1988) as described by Kröger and Schwarz (1990).

The inner limiting membrane from E8 retinas was isolated according to Halfter et al. (1987). The tectal external limiting membrane was prepared as described by Kröger and Niehörster (1990). Acid-washed coverslips were coated with purified proteins according to Bonhoeffer and Huf (1985). Native collagen was isolated according to Elsdale and Bard (1972). Vitronectin was obtained from Calbiochem (Frankfurt, Germany). Fibronectin, heparan sulfate, chondroitin sulfate, and poly-L-lysine were purchased from Sigma (Munich, Germany).

Neuroepithelial cells were obtained by triturating E2.5 eye anlagen (prepared according to Halfter and Deiss [1986]) and E3 optic tectum (dissected as described by Kröger and Schwarz [1990]) with a fire-polished Pasteur pipette. Care was taken that the dissected eye anlage did not contain remnants of the optic stalk. In the case of the optic tectum, the ventral tegmentum was discarded so that the neuroepithelial cells were derived only from the dorsal part, the area that is invaded by retinal axons at later stages. E2.5 retinas and E3 tecta were chosen, since these stages represent the most homogeneous population of neuroepithelial cells and should contain only minor amounts of other cell types (Halfter and Deiss, 1986; Kröger and Schwarz, 1990). In addition, the optic tectum is not vascularized at this embryonic age, and therefore, endothelial cells should not be present in the cultures. Neuroepithelial cells appear as flat migratory cells when seeded on the basement membrane and can clearly be distinguished morphologically from process-bearing neurons. In addition, they were immunoreactive for N-CAM in culture, but did not stain with anti-G4 antibodies, consistent with them being neuroepithelial cells. To examine the interaction of single neuroepithelial cells with retinal and tectobulbar axons, explant stripes and cells were explanted at the same time, then cultured together for $36 \mathrm{hr}$ and fixed in $4 \%$ paraformaldehyde. In this case, approximately 200 cells were seeded on every retinal basal lamina, which covered an area of about $1 \mathrm{~cm}^{2}$. To examine the growth behavior of retinal and tectobulbar axons on monolayers of neuroepithelial cells, the cells were seeded at high density and kept in culture until they had formed a confluent monolayer (usually $24 \mathrm{hr}$ ). Explant stripes labeled with rhodamine $\beta$-isothiocyanate (RITC) (see below) were placed on top of the monolayer and held in position with two metal bars as described by Walter et al. (1987).

\section{Explants on Coated Nitrocellulose}

Thin and transparent sheets of nitrocellulose bound to petri dishes were prepared under sterile conditions as described by Lagenaur and Lemmon (1987). The nitrocellulose was coated for $2 \mathrm{hr}$ with $\mathbf{4 0} \mu \mathrm{l}$ of laminin $(1 \mathrm{mg} / \mathrm{ml}$ in PBS; E.Y. Labs, San Mateo, CA) or affinity-purified G4 $(0.3 \mathrm{mg} / \mathrm{ml}$ in carbonate buffer; Rathjen et al., 1987). The drops were spread until they covered a surface of approximately $0.5 \mathrm{~cm}^{2}$. The outline of each drop was marked on the bottom of the dish. The nitrocellulose was subsequently saturated in serum-containing culture medium for $2 \mathrm{hr}$. Stripes of retinal and tectal tissue were explanted on the coated areas of the moist nitrocellulose. The tissue was pressed to the substrate by little metal bars (Walter et al., 1987) to ensure direct contact of the explant to the substrate. After incubation for 18 $\mathrm{hr}$ (retinal explants) or $40 \mathrm{hr}$ (tectobulbar explants), the tissue was fixed by adding formalin directly to the culture medium to a final concentration of $4 \%$. Specimens were viewed under phasecontrast optics in an inverted microscope.

\section{Culture of Tectobulbar Axons on Membrane Carpets}

Membrane fragments were prepared from E5 and E16 optic tecta as described by Walter et al. (1987). They were immobilized on a Nucleopore filter as a homogeneous layer or arranged as carpets consisting of alternating lanes ( $90 \mu \mathrm{m}$ wide) of E5 and E16 tectal membrane fragments. In the case of the striped carpets, one membrane preparation was labeled by the addition of fluorescein isothiocyanate (FITC) beads to the preparation $(0.5 \mu \mathrm{m}$ diameter). These beads had no influence on the growth-supporting activity of the membranes (Walter et al., 1987). Tectal axons were labeled in vitro with RITC (Sigma, Munich, Germany) by placing a piece of RITC-containing agar ( $0.1 \%$ RITC suspended in Hank's solution with $1 \%$ agar) on top of the meningeal side of the optic tectum whole mount for 5-10 $\mathrm{min}$. After staining, the tectum was kept for $1 \mathrm{hr}$ in culture medium to remove unbound RITC. The whole mount was then cut into $250 \mu \mathrm{m}$ wide strips in the anterior-posterior direction (Kröger and Schwarz, 1990). Two strips were explanted on each carpet perpendicular to the membrane stripes. The explants were held in position by metal bars and cultured for $48 \mathrm{hr}$. At the end of the incubation, the cultures were fixed overnight ( $4 \%$ paraformaldehyde, $0.33 \mathrm{M}$ sucrose), washed in deionized water, placed on a coverslip, and dried (Walter et al., 1987). FITC fluorescence showed the labeled membrane strips, and RITC fluorescence evaluated outgrowth of tectobulbar axons.

\section{Cocultures of Retinal and Tectobulbar Axons}

E6 retinal explants of nasal or temporal origin were obtained by cutting retinal whole mounts parallel to the optic fissure as described by Halfter et al. (1983). Anterior or posterior tectobulbar axons were prepared according to Kröger and Schwarz (1990). Explant pairs were placed on a retinal basal lamina at a distance of approximately $600 \mu \mathrm{m}$ and at a slight angle to each other. Explants were cultured, and axonal outgrowth was recorded by time-lapse video-phase microscopy as described by Kapfhammer et al. (1986). A few criteria were defined for comparison of results from different experiments:

- Growth cones were observed at least $\mathbf{3 0} \mathrm{min}$ in advance of a possible encounter. Only those growth cones whose speed of elongation was constantly at least $30 \mu \mathrm{m} / \mathrm{hr}$ for tectobulbar and $60 \mu \mathrm{m} / \mathrm{hr}$ for retinal axons were selected.

-Only single growth cones that contacted single neurites or 
very small axon bundles were selected. Since tectobulbar axons in vitro grow in fascicles, $F(a b)_{2}$ fragments of anti-G4 polyclonal antibodies (Rathjen et al., 1987) were included in the culture medium (final concentration $0.25 \mathrm{mg} / \mathrm{ml}$ ). This had no effect on the growth cone behavior and the speed of axonal elongation, but defasciculated tectobulbar axons (Kröger and Schwarz, 1990).

-Only those cases in which the angle between growth cone and contacted neurite was approximately $90^{\circ}$, corresponding to the in vivo orientation of both axon types, were observed.

- The growth cone as well as the contacted neurite had to be unambiguously identified by tracing them back to the corresponding explant stripe.

\section{Acknowledgments}

We would like to thank F. Rathjen for the generous gift of anti-G4 $F(a b)_{2}$ fragments as well as affinity-purified G4 protein, S. HenkeFahle for the Q211 antibody., M. Nagel for expert assistance, R. Braun and I. Zimmermann for EPON embedding and semithin sectioning, D. Eder for drawing Figure 1, and R. Marshall for skillful photographic reproductions. We are especially indebted to U. Schwarz and F. Bonhoeffer, in whose departments the work was carried out. We are grateful to $B$. Wallace for careful reading of the manuscript and many helpful suggestions.

The costs of publication of this article were defrayed in part by the payment of page charges. This article must therefore be hereby marked "advertisement" in accordance with 18 USC Section 1734 solely to indicate this fact.

Received October 29, 1990; revised December 20, 1990.

\section{References}

Adler, R., Jerdan, J., and Hewitt, A. T. (1985). Responses of cultured neural retinal cells to substratum-bound laminin and other extracellular matrix molecules. Dev. Biol. 112, 100-114.

Alvarado-Mallart, R. M., and Sotelo, C. (1984). Homotopic and heterotopic transplantations of quail tectal primordia in chick embryos: organization of the retinotectal projections in the chimeric embryos. Dev. Biol. 103, 378-398.

Bixby, J. L., Pratt, R. S., Lilien, J., and Reichardt, L. F. (1987). Neurite outgrowth on muscle cell surfaces involves extracellular matrix receptors as well as $\mathrm{Ca}^{2+}$-dependent and -independent cell adhesion molecules. Proc. Natl. Acad. Sci. USA 84, 2555-2559.

Bixby, J. L., Lilien, J., and Reichardt, L. F. (1988). Identification of the major proteins that promote neuronal process outgrowth on Schwann cells in vitro. J. Cell Biol. 107, 353-361.

Bonhoeffer, F., and Huf, J. (1982). In vitro experiments on axon guidance demonstrating an anterior-posterior gradient on the tectum. EMBO J. 1, 427-431.

Bonhoeffer, F., and Huf, J. (1985). Position-dependent properties of retinal axons and their growth cones. Nature 315, 409-410.

Boxberg, Y. von, Wütz, R., and Schwarz, U. (1990). Use of the biotin-avidin system for labelling, isolation and characterization of neural cell-surface proteins. Eur. J. Biochem. 190, 249-256.

Bray, D., Wood, P., and Bunge, R. P. (1980). Selective fasciculation of nerve fibres in culture. Exp. Cell Res. 130, 241-250.

Cohen, J., Burne, J. F., McKinlay, C., and Winter, J. (1987). The role of laminin and the laminin/fibronectin receptor complex in the outgrowth of retinal ganglion cell axons. Dev. Biol. 122, 407418.

Edelman, G. M. (1983). Cell adhesion molecules. Science 219, 450-457.

Elsdale, T., and Bard, J. (1972). Collagen substrata for studies on cell behavior. J. Cell Biol. 54, 626-637.

Goldberg, S. (1974). Studies on the mechanics of development of the visual pathways in the chick embryo. Dev. Biol. 36, 24-43.

Goldberg, S. (1977). Unidirectional, bidirectional and random growth of embryonic optic axons. Exp. Eye Res. 25, 399-404.
Halfter, W. (1988). Aberrant optic axons in the retinal pigment epithelium during chick and quail visual pathway development. J. Comp. Neurol. 268, 161-170.

Halfter, W., and Deiss, S. (1984). Axon growth in embryonic chick and quail retinal whole mounts in vitro. Dev. Biol. 102, 344-355. Halfter, W., and Deiss, S. (1986). Axonal pathfinding in organcultured embryonic avian retinae. Dev. Biol. 114, 296-310.

Halfter, W., and Fua, C. S. (1987). Immunohistochemical Jocalization of laminin, neural cell adhesion molecule, collagen type IV and T-61 antigen in the embryonic retina of the Japanese quail by in vivo injection of antibodies. Cell Tissue Res. 249, 487-496. Halfter, W., Claviez, M., and Schwarz, U. (1981). Preferential adhesion of tectal membranes to anterior embryonic chick retina neurites. Nature 292, 67-70.

Halfter, W., Newgreen, D. F., Sauter, J., and Schwarz, U. (1983). Oriented axon outgrowth from avian embryonic retinae in culture. Dev. Biol. 95, 56-64.

Halfter, W., Reckhaus, W., and Kröger, S. (1987). Nondirected axonal growth on basal lamina from avian embryonic neural retina. J. Neurosci. 7, 3712-3722.

Hamburger, V., and Hamilton, H. L. (1951). A series of normal stages in the development of the chick embryo. J. Morphol. 38 , 48-92.

Hankin, M. H., and Lund, R. D. (1987). Role of the target in directing the outgrowth of retinal axons: transplants reveal surfacerelated and surface-independent cues. J. Comp. Neurol. 263, 455-466.

Harris, W. A. (1986). Homing behaviour of axons in the embryonic vertebrate brain. Nature 320, 266-269.

Haydon, P. G., McCobb, D. P., and Kater, S. B. (1984). Serotonin selectively inhibits growth cone motility and synaptogenesis of specific identified neurons. Science 226, 561-564.

Kapfhammer, J. P., and Raper, J. A. (1987a). Collapse of growth cone structure on contact with specific neurites in culture. J. Neurosci. 7, 201-212.

Kapfhammer, J. P., and Raper, J. A. (1987b). Interactions between growth cones and neurites growing from different neural tissues in culture. J. Neurosci. 7, 1595-1600.

Kapfhammer, J. P., Grunewald, B. E., and Raper, J. A. (1986). The selective inhibition of growth cone extension by specific neurites in culture. J. Neurosci. 6, 2527-2534.

Katz, M. J., Lasek, R. J., and Nauta, H. J. W. (1980). Ontogeny of substrate pathways and the origin of the neural circuit pattern. Neuroscience 5, 821-833.

Kröger, S., and Niehörster, L. (1990). Isolation, characterization and substrate properties of the external limiting membrane from the avian embryonic optic tectum. J. Neurosci. Res. 27, 169-183. Kröger, S., and Schwarz, U. (1990). The avian tectobulbar tract: development, explant culture and effects of antibodies on the pattern of neurite outgrowth. J. Neurosci. 10, 3118-3134.

Lagenaur, C., and Lemmon, V. (1987). An L1-like molecule, the 809 antigen, is a potent substrate for neurite extension. Proc. Natl. Acad. Sci. USA 84, 7753-7757.

LaVail, J. H., and Cowan, W. M. (1971). The development of the chick optic tectum. I. Normal morphology and cytoarchitectonic development. Brain Res. 28, 391-419.

Letourneau, P. C. (1975). Cell-to-substrate adhesion and guidance of axonal elongation. Dev. Biol. 44, 92-101.

Letourneau, P. C., Madsen, A. M., Palm, S. L., and Furcht, L. T. (1988). Immunoreactivity for laminin in the developing ventral longitudinal pathway of the brain. Dev. Biol. 125, 135-144.

Liesi, P., and Silver, J. (1988). Is ast rocyte laminin involved in axon guidance in the mammalian CNS? Dev. Biol. 130, 774-785.

Linser, P. J., and Perkins, M. (1987). Gliogenesis in the embryonic avian optic tectum: neuronal-glial interactions influence astroglial phenotype maturation. Dev. Brain Res. 37, 277-290.

Mattson, M. P., Don, P., and Kater, S. B. (1988). Outgrowthregulating actions of glutamate in isolated hippocampal pyrami- 
dal neurons. J. Neurosci. 8, 2087-2100.

McCobb, D. P., Haydon, D. G., and Kater, S. B. (1988). Dopamine and serotonin inhibition of neurite elongation of different identified neurons. J. Neurosci. Res. 19, 19-26.

McLoon, S. C., and Lund, R. D. (1982). Transient retinofugal pathways in the developing chick. Exp. Brain Res. 45, 277-284.

O'Leary, D. D. M., Gerfen, C., and Cowan, W. M. (1983). Development and restriction of the ipsilateral retinofugal projections in the chick. Dev. Brain Res. 10, 93-109.

Puelles, L., and Bendala, M. C. (1978). Differentiation of neuroblasts in the chick optic tectum up to eight days of incubation: a Golgi study. Neuroscience 3, 307-325.

Rager, G. H. (1980). Development of the retinotectal projection in the chicken. Adv. Anat. Embryol. Cell Biol. 63.

Raper, J. A., and Grunewald, E. B. (1990). Temporal retinal growth cones collapse on contact with nasal retinal axons. Dev. Neurol. $109,70-74$

Rathjen, F. G., Wolff, J. M., Frank, R., Bonhoeffer, F., and Rutishauser, U. (1987). Membrane glycoproteins involved in neurite fasciculation. J. Cell Biol. 104, 343-353.

Rogers, S. L., Letourneau, P. C., Palm, S. L., McCarthy, J., and Furcht, L. T. (1983). Neurite extension by peripheral and central nervous system neurons in response to substratum-bound fibronectin and laminin. Dev. Biol. 98, 212-220.

Rösner, H., Greis, C., and Henke-Fahle, S. (1988). Developmental expression in embryonic rat and chicken brain of a polysialoganglioside-antigen reacting with the monoclonal antibody Q211. Dev. Brain Res. 42, 161-171.

Sanes, J. R. (1989). Extracellular matrix molecules that influence neural development. Annu. Rev. Neurosci. 12, 491-516.

Silver, J. (1984). Studies on the factors that govern directionality of axonal growth in the embryonic optic nerve and at the chiasm of mice. J. Comp. Neurol. 223, 238-251.

Silver, J., Poston, M., and Rutishauser, U. (1987). Axon pathway boundaries in the developing brain. I. Cellular and molecular determinants that separate the optic and olfactory projections. J. Neurosci. 7, 2264-2272.

Smalheiser, N. U., Crain, S. M., and Reidl, M. (1984). Laminin as a substrate for retinal axons in vitro. Dev. Brain Res. 12, 136-140.

Thanos, S., and Bonhoeffer, F. (1984). Development of the transient ipsilateral retinotectal projection in the chick embryo: a numerical fluorescence-microscopic analysis. J. Comp. Neurol. 224, 407-414.

Tomaselli, K. J., Neugebauer, K. M., Bixby, J. L., Lilien, J., and Reichardt, L. F. (1988). N-cadherins and integrins: two receptor systems that mediate neurite outgrowth on astrocyte surfaces. Neuron 1, 33-43.

Vanselow, J., Thanos, S., Godement, P., Henke-Fahle, S., and Bonhoeffer, F. (1989). Spatial arrangement of radial glia and ingrowing retinal axons in the chick optic tectum during development. Dev. Brain Res. 45, 15-27.

Walter, J., Kern-Veits, B., Huf, J., Stolze, B., and Bonhoeffer, F. (1987). Recognition of position-specific properties of tectal cell membranes by retinal axons in vitro. Development 101, 685-696. Wictorin, K., Brundin, P., Gustavii, B., Lindvall, O., and Björklund, A. (1990). Reformation of long axon pathways in adult rat central nervous system by human forebrain neuroblasts. Nature 347, 556-558.

Zipser, B., Morell, R., and Bajt, M. L. (1989). Defasciculation as a neuronal pathfinding strategy: involvement of a specific glycoprotein. Neuron 3, 621-630. 